\title{
The frequency and severity of dental caries, and counts of cariogenic bacteria in rheumatoid arthritis patients
}

\section{Częstość występowania i intensywność próchnicy oraz liczba bakterii próchnicotwórczych u pacjentów z reumatoidalnym zapaleniem stawów}

\author{
Rita Elizabeth Martinez-Martinez ${ }^{1,2, A, E, F}$, Rubén Abraham Domínguez-Pérez 1,3,B-D,F, Javier Sancho-Mata 2,B,C,F, Carlos Abud-Mendoza ${ }^{4, C, E, F}$, \\ José Luis Ayala-Herrera ${ }^{1,5, B, F}$, Elena Aurora Popoca-Hernandez ${ }^{1, B, F}$ \\ ${ }^{1}$ Department of Biomedical Sciences, Faculty of Medicine, Autonomous University of San Luis Potosí, Mexico \\ ${ }^{2}$ Department of Advanced General Dentistry, Faculty of Stomatology, Autonomous University of San Luis Potosí, Mexico \\ ${ }^{3}$ Laboratory of Multidisciplinary Dentistry Research, Faculty of Medicine, Autonomous University of Querétaro, Santiago de Querétaro, Mexico \\ ${ }^{4}$ Regional Unit of Rheumatology and Osteoporosis at Dr. Ignacio Morones Prieto Central Hospital, Autonomous University of San Luis Potosí, Mexico \\ ${ }^{5}$ Faculty of Dentistry, University of De La Salle Bajío, Leon, Mexico \\ A - research concept and design; $\mathrm{B}$ - collection and/or assembly of data; $\mathrm{C}$ - data analysis and interpretation; \\ $D$ - writing the article; $E$ - critical revision of the article; $F$ - final approval of the article
}

Address for correspondence

Rita Martinez-Martinez

E-mail: rita.martinez35@yahoo.com

\section{Funding sources}

This research was supported by the National Council of Science and Technology: CONACYT CB-2014-01 (grant No. 242939) and CONACYT INFR-2014-01 (grant No. 226467).

Conflict of interest

None declared

Received on December 31, 2018

Reviewed on February 5, 2019

Accepted on March 4, 2019

Published online on June 28, 2019

Cite as

Martinez-Martinez RE, Domínguez-Pérez RA, Sancho-Mata J, Abud-Mendoza C, Ayala-Herrera LL, Popoca-Hernandez EA. The frequency and severity of dental caries, and counts of cariogenic bacteria in rheumatoid arthritis patients. DentMed Probl. 2019;56(2):137-142. doi:10.17219/dmp/105340

DOI

$10.17219 / \mathrm{dmp} / 105340$

Copyright

๑ 2019 by Wroclaw Medical University

This is an article distributed under the terms of the

Creative Commons Attribution 3.0 Unported License (CC BY 3.0)

(https://creativecommons.org/licenses/by/3.0/)

\begin{abstract}
Background. It has been reported that patients with rheumatoid arthritis (RA) are more likely to exhibit periodontitis than patients without RA. However, the frequency and severity of dental caries in patients with RA is still unknown.

Objectives. The aim of the study was to investigate whether higher counts of cariogenic bacteria are present in RA patients in contrast to healthy subjects, and to ascertain whether the frequency and severity of dental caries are increased in RA patients.

Material and methods. The study involved 160 adults: an RA group $(n=80)$ and a control group matched by age and gender $(n=80)$. The participants'dental status scores were determined based on the following indices: the Decayed, Missing and Filled Teeth (DMFT) index, the Filled and Sound Teeth (FS-T) index, Treatment Needs Index (TNI), Care Index (CI), and Integrative Dental Caries Index (IDCI). DNA copies of Streptococcus mutans (S. mutans) and Streptococcus sobrinus (S. sobrinus) were quantified using realtime polymerase chain reaction (PCR).

Results. The IDCI showed that the RA group was more affected, mainly presenting moderate to severe dental caries. The RA group also had higher global DMFT scores than the control group and scored higher on the decayed component of the DMFT index. The TNI and Cl indicated that RA patients required more dental attention and appropriate treatment. The Streptococcus mutans count was significantly higher in the RA group.

Conclusions. A complete basic oral examination, along with oral health instruction including adequate oral and dental hygiene, is crucial to prevent dental caries and associated complications in RA patients, since they appear to be more vulnerable than the non-RA population.
\end{abstract}

Key words: rheumatoid arthritis, dental caries, Streptococcus mutans, Streptococcus sobrinus

Słowa kluczowe: reumatoidalne zapalenie stawów, próchnica, Streptococcus mutans, Streptococcus sobrinus 


\section{Introduction}

Rheumatoid arthritis (RA) is a chronic destructive inflammatory disease consisting in joint damage and bone erosion, and leading to functional disability. ${ }^{1}$ It has a prevalence of approx. $1 \%$ and is characterized by substantial morbidity and accelerated mortality. ${ }^{2,3}$ It is accompanied in many cases by oral manifestations, such as temporomandibular joint disorders, secondary Sjögren's syndrome and xerostomia. ${ }^{4-6}$ Xerostomia is related to hyposalivation, which is considered a cariogenic condition, since saliva plays an important role in preventing the development of dental caries. Saliva dilutes carbohydrates and other substances, has excellent buffering capacity and antimicrobial activity, and balances the enamel demineralization and remineralization. ${ }^{7}$

Dental caries is regarded as a preventable non-communicable disease that affects a majority of the population across their lifespan and, along with periodontal disease, is considered the most important oral disease. ${ }^{8,9}$ Approximately 300 bacterial species have been found to be associated with dental plaque, but only Streptococcus mutans (S. mutans) and Streptococcus sobrinus (S. sobrinus) have been consistently linked to the etiology of human dental caries. ${ }^{10}$ Additionally, S. mutans and S. sobrinus have been associated with non-oral infections, such as subacute bacterial endocarditis, atherosclerosis, coronary artery disease, and other systemic conditions. ${ }^{11,12}$

It has been reported that patients with RA are more likely to exhibit advanced periodontitis than patients without RA. ${ }^{13,14}$ However, it is still unknown whether the frequency and/or severity of dental caries is also higher in RA patients. Therefore, the aim of this study was to investigate the frequency and severity of dental caries by the use of several indices, and to detect, quantify and compare the number of DNA copies of S. mutans and S. sobrinus per milligram of supragingival dental plaque using real-time polymerase chain reaction (PCR) in RA patients and healthy subjects.

\section{Material and methods}

\section{Subject population and clinical evaluation}

This cross-sectional prospective study included 80 RA patients who were undergoing treatment and routine follow-up at the Regional Unit of Rheumatology and Osteoporosis at Dr. Ignacio Morones Prieto Central Hospital in San Luis Potosí, Mexico. All the RA patients had been diagnosed at least 5 years earlier by a rheumatologist, in accordance with the American College of Rheumatology (ACR) criteria ${ }^{15}$; they were selected for the study by non-probabilistic consecutive sampling. A control group of 80 healthy subjects (without RA), matched by age and gender with the RA group, were recruited from the waiting room of the Clinic of Oral Medicine within the Master's Degree in Advanced General Dentistry Program at the Autonomous University of San Luis Potosí. Informed and voluntary written consent was obtained prior to the clinical examinations, in accordance with the ethical principles of the Declaration of Helsinki (2013 version). The study was approved by the clinical research committee for the Master's Degree in Advanced General Dentistry Program at the Autonomous University of San Luis Potosí. In both groups, only individuals that had brushed their teeth $3 \mathrm{~h}$ before sample collection were included. Those who had undergone prophylaxis or antibiotic therapy in the previous 3 months, smokers, those suffering from infectious diseases or other chronic diseases, immunocompromised individuals, and those presenting $<8$ teeth were excluded from the study. Additionally, patients diagnosed with secondary Sjögren's syndrome and those whose RA had lasted $>15$ years were excluded from the RA group.

\section{Dental caries assessment}

Each subject completed an oral health questionnaire, which included questions about the use of oral hygiene aids, the regularity of dental check-ups and oral dryness, among others. The participants were diagnosed by a single examiner using standardized dental caries detection measures, with a standard dental light, a plain mouth mirror and a probe. For dental caries diagnosis, the total surfaces of all erupted teeth were assessed by applying the Decayed, Missing and Filled Teeth (DMFT) index and the Filled and Sound Teeth (FS-T) index, determined using the previously reported criteria for healthy and functional teeth. ${ }^{16,17}$ Treatment Needs Index (TNI), Care Index (CI) and Integrative Dental Caries Index (IDCI) were also assessed. ${ }^{18,19}$ The IDCI included clinical findings by tooth surface and tooth area (anterior and posterior teeth) per patient.

Dental caries was evaluated on the mesial, buccal, distal, and palatine surfaces of the anterior teeth (the maxillary and mandibular central and lateral incisors as well as canines). For the posterior teeth, the occlusal, mesial, buccal, distal, and palatine surfaces were evaluated in the maxillary and mandibular premolars and molars. The third molars of the 4 quadrants were excluded. In order to provide more details, the severity of dental caries was determined using a gradient that evaluated the affected anterior and posterior surfaces: healthy (a patient without dental caries); mild (1-7 surfaces affected); moderate (8-21 surfaces affected); and severe ( $>22$ surfaces affected by dental caries).$^{19}$

\section{Sample collection, DNA isolation and quantitative polimerase chain reaction}

From each participant, supragingival dental plaque was collected from 4 locations around each tooth (vestibular, mesial, palatine, and distal of anterior, posterior, upper, 
and lower teeth) using a Gracey curret (Hu-Friedy $\mathrm{Mfg}$. Co. LLC, Chicago, USA). Dental plaque was stored in a microcentrifuge tube containing the phosphate buffered saline (PBS) solution, then weighed in milligrams and washed; it subsequently underwent the DNA extraction in accordance with the previously reported protocol for Gram-positive bacteria. ${ }^{20}$ All samples were processed aseptically to prevent contamination from the environment during the DNA extraction and quantitative polymerase chain reaction (q-PCR) assays.

For q-PCR, $20 \mu \mathrm{L}$ of a mixture containing $50 \mathrm{ng}$ of genomic DNA, $1 \times$ TaqMan $^{\circledR}$ Universal PCR Master Mix (Applied Biosystems, Foster City, USA) and $0.5 \mathrm{~mL}$ of Custom TaqMan Gene Expression Assay for $S$. $m u$ tans and S. sobrinus (Applied Biosystems) (Table 1) was placed in each well of a 48-well plate. The amplification and detection were performed using the StepOne ${ }^{\mathrm{TM}}$ System (Applied Biosystems) with the cycling profiles indicated in the manufacturer's instructions. Standard curves were prepared using plasmidic DNA cloned into a vector in Escherichia coli competent cells by a 10-fold dilution series. The q-PCR results were expressed as the number of copies of bacteria DNA per milligram of dental plaque. ${ }^{21}$

\section{Statistical analysis}

All quantitative data were expressed as mean, standard deviation $(S D)$ and range. Qualitative data were expressed as frequency and proportion. Statistical differences between groups were determined with the Mann-Whitney $U$ test for quantitative variables and the $X^{2}$ test for qualitative variables. The JMP ${ }^{\circledR}$ software v. 9.0 (SAS Institute, Cary, USA) and Stata v. 11.0 (StataCorp, College Station, USA) were used. Statistical significance was set at $p<0.05$.

\section{Results}

The inter-observer reliability regarding the dental caries diagnosis was analyzed with the $\kappa$ test; the obtained $\kappa$-value was 0.90 . For both groups of participants, the mean age was $46 \pm 8$ years (range: $32-60$ years); the distribution was $92 \%$ females and $8 \%$ males. There were no statistically significant differences between the groups with respect to the oral behavior variables (Table 2 ). In the RA group, $60 \%$ of the patients reported a dry mouth sensation, whereas only $8.7 \%$ of the healthy subjects reported it $(p<0.05)$.
Regarding the DMFT index, the control group had a higher mean; however, there was no statistical difference between the 2 groups. It is important to note that the RA group had a higher rate of decayed teeth, but a lower count of filled teeth compared to the control group. These values can be translated into the high TNI and low CI found in the RA group, both with statistical significance (Table 3).

Table 4 shows IDCI, which provides more detailed information about the presence of caries by patient, tooth and surface. The dental caries gradient by patient was similar in the 2 groups, with a high frequency of mild caries (1-7 surfaces affected): $41.2 \%$ in the control group and $31.2 \%$ in the RA group. The analysis by tooth showed posterior and upper teeth as the most frequently affected, especially in RA

Table 2. Oral behavior overview in both groups

\begin{tabular}{|l|c|c|c|}
\multicolumn{1}{|c|}{ Oral behavior } & $\begin{array}{c}\text { Control group } \\
n=80\end{array}$ & $\begin{array}{c}\text { RA group } \\
n=80\end{array}$ & p-value \\
\hline $\begin{array}{l}\text { Tooth brushing } \\
\leq 1 \text { daily }\end{array}$ & $48(60)$ & $51(63.7)$ & 0.7449 \\
$\geq 2$ daily & $32(40)$ & $29(36.2)$ & \\
Use of hygiene aids & & & \\
manual toothbrush & $77(96.2)$ & $75(93.7)$ & 0.7195 \\
electric toothbrush & $3(3.7)$ & $5(6.2)$ & \\
dental floss & $41(51.2)$ & $29(36.2)$ & 0.0793 \\
mouth rinse & $33(41.2)$ & $44(55)$ & 0.1133 \\
Last dental examination & & & \\
$<12$ months ago & $22(27.5)$ & $31(38.7)$ & 0.1788 \\
$>12$ months ago & $58(72.5)$ & $49(61.2)$ & \\
\hline
\end{tabular}

Data expressed as number (percentage); RA - rheumatoid arthritis ; Fisher's exact test.

Table 3. Distribution of all the assessed indices and the Decayed, Missing and Filled Teeth (DMFT) index components

\begin{tabular}{|c|c|c|c|}
\hline \multirow{2}{*}{$\begin{array}{l}\text { Indices } \\
\text { regarding } \\
\text { teeth }\end{array}$} & $\begin{array}{l}\text { Control group } \\
\qquad n=80\end{array}$ & $\begin{array}{c}\text { RA group } \\
n=80\end{array}$ & \multirow[t]{2}{*}{$p$-value } \\
\hline & \multicolumn{2}{|c|}{ mean $\pm S D$ (range) } & \\
\hline Healthy & $13.34 \pm 5.51(2-26)$ & $15.25 \pm 5.08(4-25)$ & 0.0691 \\
\hline Decayed & $3.88 \pm 4.05(0-14)$ & $5.79 \pm 3.98(0-17)$ & $0.0149 *$ \\
\hline Missing & $4.00 \pm 3.88(0-16)$ & $3.90 \pm 3.35(0-15)$ & 0.9999 \\
\hline Filled & $6.74 \pm 4.98(0-18)$ & $3.33 \pm 3.99(0-16)$ & 0.0004 * \\
\hline DMFT & $14.84 \pm 5.52(2-26)$ & $13.02 \pm 4.99(3-24)$ & 0.0745 \\
\hline FS-T & $71.59 \pm 18.80(21-100)$ & $66.02 \pm 19.23(14-96)$ & 0.1364 \\
\hline TNI & $35.85 \pm 35.22(0-100)$ & $67.77 \pm 34.00(0-100)$ & $0.0002 *$ \\
\hline $\mathrm{Cl}$ & $45.11 \pm 30.21(0-100)$ & $23.91 \pm 27.00(0-94)$ & $0.0009 *$ \\
\hline
\end{tabular}

$\mathrm{Cl}$ - Care Index; FS-T - Filled and Sound Teeth index; SD - standard deviation; $\mathrm{TNI}$ - Treatment Needs Index; ${ }^{*}$ statistically significant (Mann-Whitney $U$ test).

Table 1. Primers and probes for qualitative polymerase chain reaction (q-PCR)

\begin{tabular}{|l|c|c|c|}
\hline \multicolumn{1}{|c|}{ Accessed bacteria } & Forward primer sequence & Reverse primer sequence & TaqMan probe \\
\hline Streptococcus mutans & GCCTACAGCTCAGA GATGCTATTCT & GCCATACACCACTC ATGAATTGA & TGGAAATGACGGTG CCGTTATGAA \\
Streptococcus sobrinus & TTCAAAGCAAGA CCAAGCTAGT & CCAGCCTGAGATTC AGCTTGT & CCTGCTCCAGCGA CAAAGGCAGC \\
\hline
\end{tabular}


patients: on average 5.3 and 4.0 teeth, respectively, as opposed to 2.4 teeth in the control group $(p<0.05)$. The global score of dental caries by surface showed that RA patients presented a significantly higher level of affected surfaces: about 7.9 compared to 5.6 in the control group $(p<0.05)$.

With respect to cariogenic bacteria, the results showed their presence in an order of magnitude of $10^{8}$ copies $/ \mathrm{mg}$ of subgingival dental plaque (Table 5). Streptococcus mutans was significantly higher in the RA patients $(p<0.05)$, while $S$. sobrinus counts were higher than $S$. mutans in both study groups $(p<0.05)$.

Table 4. Comparisons of the Integrative Dental Caries Index (IDCI)

\begin{tabular}{|c|c|c|c|c|}
\hline \multicolumn{2}{|c|}{ IDCI components } & $\begin{array}{c}\text { Control group } \\
n=80\end{array}$ & $\begin{array}{l}\text { RA group } \\
n=80\end{array}$ & $p$-value \\
\hline \multicolumn{5}{|c|}{ Dental caries by patient ${ }^{a}$} \\
\hline \multirow{4}{*}{ Gradient } & healthy & $16(20)$ & $11(13.7)$ & \multirow{4}{*}{0.2314} \\
\hline & mild & $33(41.2)$ & $25(31.2)$ & \\
\hline & moderate & $18(22.5)$ & $25(31.2)$ & \\
\hline & severe & $13(16.2)$ & $19(23.7)$ & \\
\hline \multicolumn{5}{|c|}{ Dental caries by tooth ${ }^{b}$} \\
\hline \multirow{2}{*}{ Area } & anterior & $0.8 \pm 1.0$ & $1.0 \pm 1.1$ & 0.4227 \\
\hline & posterior & $2.4 \pm 2.2$ & $5.3 \pm 3.4$ & $0.0002^{*}$ \\
\hline \multirow{2}{*}{ Jaw } & upper & $2.4 \pm 1.7$ & $4.0 \pm 2.0$ & $0.0024^{*}$ \\
\hline & lower & $1.1 \pm 1.0$ & $2.7 \pm 1.6$ & $<0.0001^{*}$ \\
\hline \multicolumn{5}{|c|}{ Dental caries by surface ${ }^{b}$} \\
\hline \multirow{2}{*}{ Area } & anterior & $1.2 \pm 1.1$ & $1.4 \pm 1.0$ & 0.7002 \\
\hline & posterior & $3.0 \pm 3.2$ & $6.2 \pm 4.2$ & $0.0001^{*}$ \\
\hline \multirow{2}{*}{ Jaw } & upper & $3.4 \pm 2.5$ & $4.7 \pm 3.0$ & $0.0264^{*}$ \\
\hline & lower & $2.2 \pm 1.6$ & $2.8 \pm 1.6$ & 0.2013 \\
\hline \multicolumn{2}{|c|}{$\begin{array}{l}\text { Global score } \\
\text { of caries by surface }\end{array}$} & $5.6 \pm 3.3$ & $7.9 \pm 4.8$ & $0.0228^{*}$ \\
\hline
\end{tabular}

Data presented as number (percentage) or mean $\pm S D$

${ }^{a} X^{2}$ test; ${ }^{b}$ Mann-Whitney $U$ test; ${ }^{*}$ statistically significant.

Table 5. Distribution of Streptococcus mutans (S. mutans) and Streptococcus sobrinus (S. sobrinus)

\begin{tabular}{|c|c|c|c|}
\hline \multirow{2}{*}{ Bacteria } & $\begin{array}{l}\text { Control group } \\
\qquad n=80\end{array}$ & $\begin{array}{l}\text { RA group } \\
n=80\end{array}$ & \multirow{2}{*}{$p$-value } \\
\hline & \multicolumn{2}{|c|}{ mean $\pm S D$ (range) } & \\
\hline $\begin{array}{l}\text { Total of cariogenic } \\
\text { bacteria }\end{array}$ & $\begin{array}{c}4.6 \times 10^{8} \pm 3.1 \times 10^{9} \\
\left(677.3-2 \times 10^{10}\right)\end{array}$ & $\begin{array}{c}3.3 \times 10^{8} \pm 8.2 \times 10^{8} \\
\left(6483.4-4 \times 10^{9}\right)\end{array}$ & 0.7307 \\
\hline S. mutans & $\begin{array}{c}1.5 \times 10^{5} \pm 4.9 \times 10^{5} \\
\left(66.36-2.8 \times 10^{6}\right)\end{array}$ & $\begin{array}{c}5.9 \times 10^{7} \pm 1.7 \times 10^{8} \\
\left(41.72-8.9 \times 10^{8}\right)\end{array}$ & $0.0001^{*}$ \\
\hline S. sobrinus & $\begin{array}{c}9.5 \times 10^{8} \pm 5.6 \times 10^{8} \\
\left(0-3.8 \times 10^{8}\right)\end{array}$ & $\begin{array}{c}5.9 \times 10^{8} \pm 1.8 \times 10^{9} \\
\left(0-7.8 \times 10^{9}\right)\end{array}$ & 0.6712 \\
\hline$p$-value & $<0.0001^{*}$ & $0.0421^{*}$ & - \\
\hline
\end{tabular}

* statistically significant (Mann-Whitney $U$ test).

\section{Discussion}

Rheumatoid arthritis is a chronic inflammatory disorder that affects joints, which results in physical disabilities, such as arm and hand dysfunction. When hyposalivation (associated or not with Sjögren's syndrome) is involved, oral hygiene becomes a particular concern. ${ }^{22}$ In this study, we excluded patients diagnosed with secondary Sjögren's syndrome and only included patients with at least 5 years and at the longest 15 years of RA in order to limit possible injury to the salivary glands and the timespan in which the subjects could have experienced hyposialia. This was because hyposialia could affect the salivary flow and decrease the ability to neutralize acids produced as a result of bacterial metabolism, leading to changes in the oral microbiota associated with caries frequency and severity.

It is well-known that dental caries represents a major public health problem around the world, whereas RA occurs worldwide with a prevalence estimated at $0.2-1.0 \%$, affecting mainly females at a ratio of 3:1. . $3,24^{2}$ The distribution of female patients in the present study (around 13:1) was higher than in the previously reported data. This can be explained by the fact that patients were selected from a rheumatology unit by consecutive sampling. Besides, it can be inferred that women generally report for more of their rheumatologic follow-ups than men do. To the best of our knowledge, there have only been 2 studies using the DMFT index to assess caries in RA patients and controls, and both reported no significant differences between the groups (11.84 vs 10.56, respectively, in one report, ${ }^{25}$ and 17.61 vs 16.03 , respectively, in the other ${ }^{26}$ ). In the present study, we obtained a slightly higher DMFT score in the control group compared to the RA group (14.8 vs 13.0, respectively). These results are consistent with other reports of DMFT scores of 13.1 in adults older than 40 years in our population. ${ }^{27}$ Such results may be due to demographic differences. Although we found no statistically significant differences between the groups when comparing the overall DMFT index scores, analyzing each DMFT component proved that RA patients presented a higher mean of decayed teeth than the control group (5.79 vs 3.88; $p=0.0149$ ), showing that RA patients had more active caries. At the same time, the mean of filled teeth was significantly lower in the RA group compared to the control group (3.33 vs 6.74; $p=0.0004$ ). The TNI and CI confirmed these findings, showing that the RA patients had higher levels of active caries than the control group, which had more filled than decayed teeth.

It is important to note that the DMFT index represents the history of dental caries in the subject, which was similar in the 2 groups. Although the DMFT index is generally used in dental caries epidemiological studies, it is only focused on determining the caries experience during the subject's life. This is an important limitation, because it does not distinguish caries severity and assigns the same value to small lesions and highly damaged surfaces. For that reason, IDCI is useful to provide detailed information about dental caries. After analyzing all the indices, including IDCI, it is unquestionable that RA patients exhibited more dental caries (and often more severe) than the subjects without RA. 
The present study included both bacterial species associated with dental caries, and used the golden standard q-PCR - to quantify bacterial DNA copies per milligram of dental plaque. This method is highly sensitive and specific for the detection and quantification of bacteria, and is superior to classical methods, such as counting colony-forming units (CFUs), which is limited by a possible bias or the overestimation of the bacteria involved in dental caries. ${ }^{28}$

It has been widely reported that $S$. sobrinus strains are more acidogenic and aciduric, and that they exhibit a greater degree of cariogenicity in gnotobiotic animals than $S$. mutans strains. Despite these proprieties, S. sobrinus is much less frequently isolated from humans than $S$. mutans; and when isolated, it is almost invariably present in lower quantities. ${ }^{29}$ However, both of our study groups presented a high amount of $S$. sobrinus compared to $S$. mutans. This can be explained by the fact that the plaque samples were obtained from supragingival smooth surfaces, where $S$. sobrinus is more frequent than $S$. $m u$ tans, which has been linked to pits and fissures on occlusal surfaces. A previous work by our research group described similar findings in systemic lupus erythematosus (SLE) patients, where moderate to severe caries and a higher number of $S$. sobrinus copies per milligram of dental plaque were observed. ${ }^{19}$ Since both SLE and RA are autoimmune diseases, it is crucial to promote measures to prevent dental caries on all surfaces, including smooth surfaces. Oral opportunistic infections can have a considerable impact on other systemic diseases as well.

It is important to note that all the participants in our study presented both of the bacterial species that have previously been associated with a high frequency and severity of dental caries. ${ }^{30,31}$ However, the RA group presented $S$. mutans in counts that were higher compared to the controls by at least 2 orders of magnitude, which could be clinical evidence that there is high bacterial activity in these patients. The unique difference between our groups - oral dryness in the RA group - could be related to the higher counts of S. mutans in that group. A limitation of this study is that we did not perform sialometry to detect the differences in saliva secretion; we only questioned patients about a dry mouth sensation. Silvestre-Rangil et al. investigated whether a dry mouth sensation was correlated to genuine hyposialia, and observed significant differences between their control group and RA group, in which saliva rates were clearly decreased. ${ }^{25}$

\section{Conclusions}

Our results suggest that dental caries is more frequent and severe in RA patients, just as periodontal diseases were shown to be in previous studies. These results indicate that RA patients are not receiving adequate dental care, or they may be focusing their attention more on their systemic disease, considering dental care less important. Rheumatolo- gists should therefore refer patients for complete basic oral examinations and promote oral health, including adequate oral and dental hygiene, in order to prevent dental caries and its complications. Dental caries must be considered an oral manifestation that accompanies RA in many cases.

\section{ORCID iDs}

Rita Elizabeth Martinez-Martinez (D) https://orcid.org/0000-0001-9631-2751 Rubén Abraham Domínguez-Pérez (D) https://orcid.org/0000-0001-8979-8394 Javier Sancho-Mata (D) https://orcid.org/0000-0001-6240-3161 Carlos Abud-Mendoza (I) https://orcid.org/0000-0002-3749-5831 José Luis Ayala-Herrera (D) https://orcid.org/0000-0001-7732-7974 Elena Aurora Popoca-Hernandez (1) https://orcid.org/0000-0001-9076-0713

\section{References}

1. Kobayashi T, Ito S, Kuroda T, et al. The interleukin-1 and Fcy receptor gene polymorphisms in Japanese patients with rheumatoid arthritis and periodontitis. J Periodontol. 2007;78(12):2311-2318.

2. Gabriel SE, Crowson CS, O'Fallon WM. Mortality in rheumatoid arthritis: Have we made an impact in 4 decades? J Rheumatol. 1999;26(12):2529-2253.

3. Gabriel SE, Crowson CS, O'Fallon WM. Comorbidity in arthritis. J Rheumatol. 1999;26(11):2475-2479.

4. Helenius L, Tervahartiala P, Helenius I, et al. Clinical, radiographic and MRI findings of the temporomandibular joint in patients with different rheumatic diseases. Int J Oral Maxillofac Surg. 2006;35(11):983-989.

5. Gilboe IM, Kvien TK, Uhlig T, Husby G. Sicca symptoms and secondary Sjögren's syndrome in systemic lupus erythematosus: Comparison with rheumatoid arthritis and correlation with disease variables. Ann Rheum Dis. 2001;60(12):1103-1109.

6. Russell SL, Reisine S. Investigation of xerostomia in patients with rheumatoid arthritis. J Am Dent Assoc. 1998;129(6):733-739.

7. Llena-Puy $C$. The role of saliva in maintaining oral health and as an aid to diagnosis. Med Oral Patol Oral Cir Bucal. 2006;11(5):E449-E455.

8. Twetman S. Prevention of dental caries as a non-communicable disease. Eur J Oral Sci. 2018;126(Suppl 1):19-25.

9. Petersen PE, Bourgeois D, Ogawa H, Estupinan-Day S, Ndiaye C. The global burden of oral diseases and risks to oral health. Bull World Health Organ. 2005;83(9):661-669.

10. Koga T, Oho T, Shimazaki Y, Nakano Y. Immunization against dental caries. Vaccine. 2002;20(16):2027-2044.

11. Herzberg MC, Meyer MW, Kiliç A, Tao L. Host-pathogen interactions in bacterial endocarditis: Streptococcal virulence in the host. Adv Dent Res. 1997;11(1):69-74.

12. Soto-Barreras U, Olvera-Rubio JO, Loyola-Rodriguez JP, et al. Peripheral arterial disease associated with caries and periodontal disease. J Periodontol. 2012;84(4):486-494.

13. Rutger Person G. Rheumatoid arthritis and periodontitis - inflammatory and infectious connections. Review of the literature. J Oral Microbiol. 2012;4(1):11829.

14. Loyola-Rodriguez JP, Martinez-Martinez RE, Abud-Mendoza C, Patiño-Marin N, Seymour GJ. Rheumatoid arthritis and the role of oral bacteria. J Oral Microbiol. 2010;2(1):5784.

15. Aletaha D, Neogi T, Silman AJ, et al. 2010 rheumatoid arthritis classification criteria: An American College of Rheumatology/European League Against Rheumatism collaborative initiative. Arthritis Rheum. 2010;62(9):2569-2581.

16. World Health Organization. Oral Health Surveys - Basic Methods. $4^{\text {th }}$ ed. Geneva, Switzerland: World Health Organization; 1997:39-43.

17. Namal N, Vehid S, Sheiham A. Ranking countries by dental status using the DMFT and FS-T indices. Int Dent J. 2005;55(6):373-376.

18. Martínez-Pérez KM, Monjarás-Avila AJ, Patiño-Marín N, et al. Epidemiologic study on dental caries and treatment needs in schoolchildren aged six to twelve years from San Luis Potosi. Rev Invest Clin. 2010;62(3):206-213.

19. Loyola-Rodriguez JP, Galvan-Torres LJ, Martinez-Martinez RE, et al. Frequency of dental caries in active and inactive systemic lupus erythematosus patients: Salivary and bacterial factors. Lupus. 2016;25(12):1349-1356. 
20. Martinez-Martinez RE, Abud-Mendoza C, Patiño-Marin N, Rizo Rodriguez JC, Little JW, Loyola Rodriguez JP. Detection of periodontal bacterial DNA in serum and synovial fluid in refractory rheumatoid arthritis patients. J Clin Periodontol. 2009;36(12):1004-1010.

21. Yoshida A, Suzuki N, Nakano Y, Kawada M, Oho T, Koga T. Development of a $5^{\prime}$ nuclease-based real-time PCR assay for quantitative detection of cariogenic dental pathogens Streptococcus mutans and Streptococcus sobrinus. J Clin Microbiol. 2003;41(9):4438-4441.

22. Haga HJ, Naderi Y, Moreno AM, Peen E. A study of the prevalence of sicca symptoms and secondary Sjögren's syndrome in patients with rheumatoid arthritis, and its association to disease activity and treatment profile. Int J Rheum Dis. 2012;15(3):284-288.

23. Petersen PE. Challenges to improvement of oral health in the $21^{\text {st }}$ century - the approach of the WHO Global Oral Health Programme. Int Dent J. 2004;54(6 Suppl 1):329-343.

24. KoopmanWJ.Prospectsforautoimmune disease: Research advances in rheumatoid arthritis. JAMA. 2001;285(5):648-650.

25. Silvestre-Rangil J, Bagán L, Silvestre FJ, Bagán JV. Oral manifestations of rheumatoid arthritis. A cross-sectional study of 73 patients. Clin Oral Investig. 2016;20(9):2575-2580.

26. Mühlberg S, Jäger J, Krohn-Grimberghe B, et al. Oral health-related quality of life depending on oral health in patients with rheumatoid arthritis. Clin Oral Investig. 2017;21(9):2661-2670.

27. Mejía-González AM, Lomelí-Buyoli G. Resultados del Sistema de Vig ilancia Epidemiológica de Patologías Bucales (SIVEPAB) 2010. Mexico City, Mexico: SIVEPAB; 2010:47.

28. Heid CA, Stevens J, Livak KJ, Williams PM. Real time quantitative PCR. Genome Res. 1996;6(10):986-994.

29. Homer KA, Patel R, Beighton D. Effects of N-acetylglucosamine on carbohydrate fermentation by Streptococcus mutans NCTC 10449 and Streptococcus sobrinus SL-1. Infect Immun. 1993;61(1):295-302.

30. Okada M, Soda Y, Hayashi F, et al. Longitudinal study of dental caries incidence associated with Streptococcus mutans and Streptococcus sobrinus in pre-school children. J Med Microbiol. 2005;54(Pt 7):661-665.

31. Choi EJ, Lee SH, Kim YJ. Quantitative real-time polymerase chain reaction for Streptococcus mutans and Streptococcus sobrinus in dental plaque samples and its association with early childhood caries. Int J Paediatr Dent. 2009;19(2):141-147. 